\title{
Penerapan Model Pembelajaran Jigsaw Untuk Mata Diklat Akuntabilitas Pada Pelatihan Dasar Calon Pegawai Negri Sipil Provinsi Kepulauan Bangka Belitung Tahun 2019
}

\author{
Enny Habibah \\ ${ }^{1}$ BKPSDMD Prov.Kep.Bangka Belitung
}

\section{Info Artikel : (9 pt)}

Diterima 2 september 2020

Direvisi 12 september 2020

Dipublikasikan

30 september 2020

\section{Kata Kunci: (9 pt)}

Inovasi.

Model pembelajaran jigsaw,

Pelatihan dasar CPNS

Keywords: (9pt, sejajar dengan abstrak berbahasa inggris)

Innovation.

Jigsaw learning model,

CPNS basic training

\begin{abstract}
ABSTRAK ( 9 PT)
Inovasi pembelajaran merupakan $\quad$ upaya penemuan atau pembaharuan dalam sistem pembelajaran yang dilakukan dengan tujuan mendapatkan kualitas pendidikan yang lebih baik, efektif dan efisien, hal mutlak harus dilakukan oleh widyaiswara. Penelitian ini bertujuan untuk mengetahui bagaimana efektivitas model pembelajaran jigsaw yang diterapkan untuk mata diklat Akuntabilitas kepada 320 peserta pelatihan dasar CPNS di lingkungan Provinsi Kepulauan Bangka Belitung tahun 2019. Penelitian dilakukan dengan pendekatan diskriptif kualitatif, menggunakan alat ukur berupa kuesioner yang berisi daftar pertanyaan yang berhubungan dengan variabel kajian. Hasil penelitian menunjukkan 18,125 \% peserta menyatakan model pembelajaran Jigsaw sangat efektif diterapkan untuk mata diklat Akuntabilitas, 71,250 peserta menyatakan model pembelajaran jigsaw efektif diterapkan untuk mata diklat Akuntabilitas, $8,125 \%$ peserta menyatakan model pembelajaran jigsaw kurang efektif diterapkan untuk mata diklat Akuntabilitas dan 2,50\% peserta menyatakan penerapan model pembelajaran jigsaw tidak efektif untuk diterapkan pada mata diklat Akuntabilitas pelatihan dasar CPNS. Dapat disimpulkan bahwa model pembelajaran jigsaw sangat efektif diterapkan untuk mata diklat Akuntabilitas pada pelatihan dasar CPNS Provinsi kepulauan Bangka Belitung tahun 2019.
\end{abstract}

\begin{abstract}
Learning innovation is an attempts to discover or renewal learning system with the aim to obtain a better, effective, and efficient quality of education, it is absolutely necessary for Widyaiswara to do this. This study aims to determine the effectiveness of the jigsaw learning model that is applied to Accountability training course for 320 CPNS' basic training participants in Bangka Belitung Province in 2019. The research was conducted with a qualitative descriptive approach using a questionnaire measuring instrument containing a list of questions related to the study variables. The results showed that $18.125 \%$ of participants in the Jigsaw learning model were very effective to be applied to the Accountability training course, $71.250 \%$ participants in the Jigsaw learning model were effective to be applied to the Accountability training course, $8.125 \%$ of participants implementing the Jigsaw learning model were less effective for the Accountability training course, and $2.50 \%$ participants applying the jigsaw learning model were not effective for the CPNS basic training accountability course. It is undeniable that the jigsaw learning model is very effective to be applied to the accountability course in the basic training of CPNS in Bangka Belitung Province in 2019.
\end{abstract}

\section{Koresponden: (9 pt)}

Enny Habibah

Email: ennyhabibah@gmail.com
This is an open access article distributed under the Creative Commons Attribution License, which permits unrestricted use, distribution, and reproduction in any medium, provided the original work is properly cited. (C2019 by author. 
Sebagai implementasi dari Undang-Undang Nomor 5 tahun 2014. Tentang Apatur Sipil Negara ${ }^{1}$ bahwa setiap calon pegawai negeri sipil wajib menjalani masa percobaan yang dilaksanakan melalui proses pelatihan yang terintegrasi, Untuk mewujudkan hal tersebut diperlukan sebuah penyelenggaraan pelatihan yang inovatif dan terintegrasi, yaitu penyelenggaraan pelatihan yang memadukan pembelajaran klasikal dan nonklasikal ditempat pelatihan dan ditempat kerja, Sehingga memungkinkan peserta mampu menginteranlisasikan, menerapakan dan mengaktualisasikan serta membuatnya menjadi kebiasaaan (habituasi) serta merasakan manfaatnya dengan harapan hal tersebut akan terpatri dalam dirinya sebagai karakter PNS yang profesional sesuai bidang tugas.

Saat ini telah dilakukan penyempurnaan dan pengayaan konsep diklat prajabatan yang dilakukan dengan mengembangkan desain diklat terintegrasi sejalan dengan perkembangan dinamika tuntutan jabatan dan pengutan terhadap kompetensi bidang. Whole of governance yang didasari nilai-nilai dasar PNS sesuai kedudukan dan peran PNS dalam NKRI pada setiap pelaksanaan tugas jabatannya sebagai pelayan masyarakat, sebagai wujud nyata bela negara seorang PNS².

Badan kepegawaian dan pengembangan sumber daya manusia daerah Provinsi Kepulauan Bangka Belitung, sebagai lembaga diklat yang terakreditasi pada tahun 2019 menyelengarakan pelatihan dasar CPNS baik untuk CPNS Provinsi maupun CPNS Kabupaten kota dengan pola kerjasama. Untuk mencapai tujuan diklat prajabatan diatas penulis sebagai widyaiswara menganggap diperlukan inovasi dan kreasi pengembangan model pembelajaran yang harus dilakukan oleh seorang widyaiswara. Sebelum menentukan suatu model pembelajaran yang akan diterapkan ada beberapa hal yang harus di pahami oleh widyaiswara pertama, widyaiswara harus memperhatikan tujuan pembelajaran, kedua widyaiswara harus tahu karakteristik peserta diklat, ketiga widyaiswara harus paham materi pembelajarannya, alokasi waktu yang disediakan dan memperhatikan kekuatan dan kegunaan semua model pembelajaran.

Hal ini akan membuat pembelajaran menjadi lebih hidup dan bermakna. Penelitian tentang pelatihan dasar CPNS sudah pernah dilakukan oleh ${ }^{3}$ diperoleh bahwa penyelenggaraan pelatihan Dasar CPNS belum efektif dari faktor widyaiswara, sarana dan waktu pelaksanaan, ini bearti perlu dilakukan inovasi inovasi agar hasil pembelajaran lebih efektif terutama inovasi pengembangan model pembelajaran.

Inovasi mutlak dilakukan terlebih memasuki era digital yang semakin canggih, dan maju seperti sekarang ini, dimana semua peserta pelatihan bisa mengakses apa yang mereka inginkan. Implikasinya inovasi pembelajaran menjadi sebuah jalan untuk menunjukkan profesionalitas widyaiswara. Berani menjadi widyaiswara harus berani berinovasi terutama dalam hal pengembangan model pembelajaran. Setelah mengetahui tujuan pembelajaran , karakteristik peserta pelatihan adalah kaum milenial, materi akuntabilitas dengan alokasi waktu 9 jam pelajaran, maka penulis memutuskan untuk menerapkan model pembelajaran jigsaw untuk mata diklat Akuntabilitas pada pelatihan dasar CPNS. Karena model pembelajaran jigsaw mempunyai beberapa kelebihan : (1) memungkinkan peserta pelatihan dapat mengembangkan kreativitas, kemamauan, dan daya pemecahan masalah menurut kehendaknya sendiri, (2) Hubungan antara widyaiswara dan peserta pelatihan berjalan secara seimbang dan memungkinkan suasana belajar menjadi sangat akrab sehingga memungkinkan harmonisasi. (3) Memotivasi widyaiswara untuk bekerja lebih aktif dan kraetif (4) Mampu memadukan berbagai pendekatan belajar, yaitu pendekatan klasikal, kelompok dan individual ${ }^{4}$.

Model pembelajaran adalah kerangka konseptual yang melukiskan prosedur yang sistematis dalam mengorganisasikan pengalaman belajar untuk mencapai tujuan belajar tertentu, dan berfungsi sebagai pedoman bagi para perancang pembelajaran dan para pengajar dalam merencanakan aktivitas belajar mengajar oleh Nurulwati, dalam ${ }^{5}$.

Model Jigsaw merupakan model belajar kooperatif dengan cara peserta belajar dalam kelompok kecil yang terdiri empat sampai dengan 6 orang secara heterogen, peserta bekerjasama saling ketergantungan positif dan bertanggungjawab secara mandiri. Dalam Model pembelajaran Jigsaw peserta banyak memiliki kesempatan untuk mengemukakan pendapat dan mengolah informasi yang didapat, dan dapat meningkatkan keterampilan berkomunikasi. materi yang dipelajari dan dapat menyampaikan kepada kelompoknya oleh Rusman dalam ${ }^{6}$.

Model pembelajaran Jigsaw ini dilakukan dengan modifikasi angkah-langkah sebagai berikut: a. Langkah Pertama

1 Tim Pustaka Yustisia, Undang-Undang No. 5 Tahun 2014 Tentang Aparatur Sipil Negara (ASN), 2014

2 LAN RI, “Peraturan Lembaga Adminitrasi Negara RI No. 12," 2018.

3 Israwati, "Efektifitas Pelaksanaan Diklat Prajabatan Pada Badan Kepegawaian Pendidikan Dan Pelatihan Kabupaten Mamasa,"

Mitzal, Jurnal Ilmu Pemerintahan \& Ilmu Komunikasi 4, no. 2 (2019): 171-87.

${ }^{4}$ Aris Shoimin, 68 Model Pembelajaran Inovatif Dalam Kurikulum 13 (Yogyakarta: Ar-Ruzz Media, 2016).

${ }^{5}$ Shoimin.

${ }^{6}$ Shoimin. 
Widyaiswara merencanakan pembelajaran yang akan menghubungkan beberapa konsep dalam satu rentang waktu secara bersamaan, dalam hal ini pada mata diklat Akuntabilitas, peserta akan mempelajari (1) Konsep Akuntabilatas.(2).Mekanisme Akuntabilitas (3) Akuntabilitas dalam konteks.(4) menjadi PNS yang akuntabel.

b. Langkah Kedua

Siapkan handout materi pelajaran untuk masing masing konsep, sehingga widyaiswara memiliki 4 Jenis handout tentang (1) konsep Akuntabilitas (2) Mekanisme Akuntabilitas (3) Akuntabilitas dalam konteks (4) menjadi PNS yang akuntabel.

c. Langkah ketiga

Widyaiswara menyiapkan kuis sebanyak (4) jenis sesuai materi yang akan peserta pelajari

d. Langkah keempat

Membagi kelas menjadi empat kelompok.. Widyaiswara menginstruksikan agar diskusi dimulai. Masingmasing kelompok bersiap untuk mempelajari empat konsep yang telah ditentukan. Tiap kelompok terbagi dalam sub kelompok masing-masing mempelajari masing-masing satu handout . pada saat diskusi setiap subkelompok mendalami satu konsep, dan masing-masing sub kelompok bisa saling bertanya untuk memperoleh pemahaman (kelompok ini disebut home groups) di bagian akhir sesi, Jika telah memenuhi target waktu berdasarkan pemantauan peserta pelatihan telah cukup memahami materi,maka diskusi ditutup sementara waktu.

e. Langkah kelima

tidak ada interaksi antara sub kelompok. Kegiatan refleksi ini merupakan proses peningkatan penguasaaan materi untuk menghadapi babak diskusi sebagai tim ahli.

f. Langkah keenam

Pada setiap subkelompok yang ahli mengenai konsep ke 1 bergabung dengan ahli konsep ke 1 dari kelompok lain. Langkah ini peserta kembali berdiskusi, setiap kelompok membahas 1 handout materi yang menjadi bidang keahliannya. Disini terdapat masa kritis yang perlu widyaiswara pantau pada tiap kelompok. Memastikan konsep yang peserta pelatihan kembangkan sesuai dengan yang seharusnya.

g. Langkah ketujuh

Setelah selesai mendalami materi melalui diskusi kelompok ahli, peserta pelatihan kembali ke kelompok awal harus memiliki catatan hasil diskusi pada tahap satu, tahap dua diskusi tim ahli dan kembali kekelompoknya semula.

h. Langkah kedelapan

Widyaiswara mengukur hasil belajar peserta pelatihan dengan test atau kuis. Widyaiswara dapat menilai tingkat ketuntasan belajar dengan cara membandingkan hasil yang peserta pelatihan capai dengan target yang diterpakan dalam rencana pembelajaran.

\section{METODE}

Penelitian tentang penerapan model pembelajaran jigsaw untuk mata diklat Akuntabilitas PNS pada pelatihan dasar calon pegawai negeri sipil Provinsi Kepuluan Bangka Belitung tahun 2019 merupakan penelitian dsekriptif dengan menggunakan pendekatan kualitatif. yaitu penelitian yang dilakukan tanpa membuat perbandingan atau menghubungkan dengan variabel yang lainnya.Instrumen atau alat ukur yang digunakan dalam penelitian ini..adalah berupa kuesioner yang berisi daftar pertanyaan yang berhubungan dengan variabel kajian. Kuesioner diberikan kepada peserta pelatihan menjelang pembelajaran mata diklat akuntabilitas berakhir dan di kembalikan setelah pembelajaran mata diklat berakhir.

\section{Populasi dan sampel}

Sasaran penelitian adalah peserta pelatihan dasar CPNS sebanyak 320 peserta pelatihan yang berasal dari 6 kabupaten 1 kota dan 1 Provinsi yang masing-masing Kabupaten Kota sebanyak 1 angkatan (40 peserta pelatihan)

\section{Lokasi dan waktu}

Penelitian dilakukan di Provinsi Kepulauan Bangka Belitung yang meliputi 6 Kabupaten dan 1 Kota yang menjadi binaan Provinsi, yang berlangsung selama 6 bulan, yang dimulai dari tanggal 12 April dan berakhir pada tanggal 17 Oktober 2019. Dalam penelitian ini penulis melakukan evaluasi dengan menggunakan model Kirpatrick dengan nama Kirpatrick Training Evaluation yang fokus pada level 4 /tahapan:

A. Level I Reaksi (Reaction)

Level Reaksi yang merupakan level pertama ,mengevaluasi terhadap reaksi peserta diklat berarti mengukur kepuasan peserta ( custamer satisfaction) program diklat dianggap efektif apabila proses diklat dirasa menyenangkan dan memuaskan bagi peserta diklat sehingga mereka tertarik, termotivasi untuk belajar dan berlatih. Sebaliknya apabila peserta diklat tidak merasa puas terhadap proses diklat yang diikutinya maka mereka tidak akan termotivasi untuk mengikuti diklat lebih lanjut. Evaluasi pada level 1 ini yang dinilai adalah penyelenggaraan diklatnya, yang menyangkut sarana, prasrana, kurikulum diklatnya. 
B. Level 2 pembelajaran (Learning)

Pada Evaluasi level learning ini Kirkpatrikck dalam Maliki (2016) learning can be defined as the extent towhich partisipants change attitudes, improve knowledge, and / or incresase skills as a result of attending the program. Ada tiga hal yang dapat diajarkan dalam program diklat, yaitu pengetahuan, sikap maupun keterampilan. perlu untuk diukur. a) pengetahuan apa yang telah dipelajari b) sikap apa yang telah berubah dan , c) keterampilan apa yang telah dikembangkan atau diperbaiki.

C. Level 3 Prilaku (Behavior)

Apakah perubahan sikap yang telah terjadi setelah mengikuti diklat juga akan diimplementasikan setelah peserta kembali ketempat kerjanya, sehingga penilaian tingkah laku ini lebih bersifat eksternalmaka level 3 ini dapat di sebut sebagai outcomes dari kegiatan diklat.

D. Level 4 hasil ( Result)

Evaluasi hasil dalam level 4 ini difokuskan pada hasil akhir (Final result) yang terjadi karena peserta telah mengikuti suatu program. Termasuk dalam katagori hasil akhir dari suatu program diklat diantaranya naiknya produksi, peningkatan kualitas, penurunan biaya, penurunan kuantitas terjadinya kecelakan kerja, penurunan turn over dan kenaikan keuntungan.Dengan kata lain adalah evaluasi terhadap Impact program.

Berkaitan dengan penelitian yang penulis lakukan maka model Kirkpatrick yang digunakan adalah pada level 2 yaitu pembelajaran (Learning), Evaluasi hasil pada level 2 ini difokuskan pada perubahan sikap saat kegiatan belajar berlangsung

Alur proses penelitian dilakukan melalui beberapa tahapan yaitu :

1. Melakukan kegiatan belajar mengajar dengan menerapkan model pembelajaran jigsaw

2. Melakukan evaluasi penguasaan materi

3. Memberikan kuesioner yang meliputi 6 item

4. Mengelola data hasil kuesioner

Score yang digunakan dalam penelitian menggunakan Skala Likert, yaitu pernyataan positif yang diberi skore $5,4,3,2,1$, dalam ${ }^{7}$

80.01 sd. 100 sangat efektif

60,01 sd. 80 efktif

40,01 sd. 60 kurang efektif

20,01 sd. 40 tidak efektif

$0 \quad$ sd. 20 sangat tidak efektif

\section{HASIL DAN PEMBAHASAN}

Penelitian ini menghasilkan data dan informasi mengenai penerapan model pembelajaran jigsaw untuk mata diklat akuntabilitas pada pelatihan dasar CPNS. di Provinsi kepulauan Bangka Belitung tahun 2019.

Mengacu kepada Peraturan Lembaga Administrasi Negara Nomior 12 Tahun 2018 tentang pelatihan dasar CPNS, penyelenggaraan dilakukan oleh lembaga diklat terakreditasi, Pemerintah Provinsi Kepulauan Bangka Belitung dalam hal ini Badan kepegawaian dan pengembangan SDM daerah menyelenggarakan pelatihan dasar CPNS bekerjasama dengan BKD seluruh kabupaten kota lingkup Provinsi Kepulauan Bangka Belitung dengan jumlah peserta maximal 40 orang dalam setiap angkatan.

1. Penyelenggaran pelatihan dasar CPNS golongan III angkatan 1 Kabupaten Belitung

Timur Tahun tanggal 12 April 2019, jumlah peserta 40 orang

2. Penyelenggaraan pelatihan dasar CPNS golongan III angkatan 2 Kabuapaten Bangka tanggal 22 April Tahun 2019, Jumlah peserta 40 orang

3. Penyelenggaraan pelatihan dasar CPNS golongan III angkatan 2 Kabupaten Bangka Selatan tanggal 30 April tahun 2019, jumlah peserta 40 orang

4. Penyelenggaraan pelatihan dasar CPNS golongan III angkatan 6 Provinsi Kepulauan Bangka Belitung tanggal 16-17 Mei tahun 2019, jumlah peserta 40 orang

5. Penyelenggaraan pelatihan dasar CPNS Golongan III angkatan 3 Kabupaten Bangka Tengah tanggal 29 Juni tahun 2019, jumlah peserta 40 orang.

6. Penyelenggaraan pelatihan dasar CPNS golongan III angkatan 6 Kabupaten Bangka Barat tanggal 2 JuliTahun 2019, jumlah peserta 40 orang.

7. Penyelenggaraan pelatihan dasar CPNS golongan III angkatan 5 Kota Pangkalpinang tanggal 27 Agustus tahun2019, jumlah peserta 40 orang.

8. Penyelenggaraan pelatihan dasar CPNS golongan III angkatan 1 Kabupaten Belitung tanggal 17 Oktober tahun 2019, jumlah peserta 40 orang.

${ }^{7}$ Agus Riyanto, Metodelogi Penelitian Kesehatan (Nuha Medika, 2019). 
Grafik I

Pelatihan dasar CPNS golongan III angkatan 1

Kabupaten Belitung Timur tahun 2019

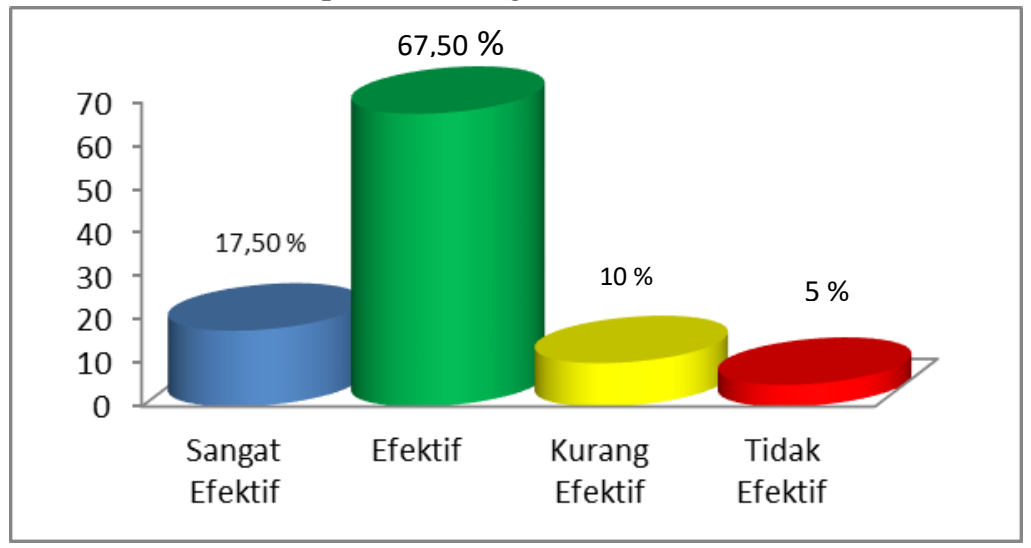

Peserta pelatihan dasar CPNS golongan III angkatan 1 Kabupaten Belitung Timur tahun 2019 berjumlah 40 peserta. Berdasarkan perhitungan kuesioner yang diisi 7 peserta atau 17,50\% menyatakan bahwa model pembelajaran jigsaw sangat efektif diterapkan untuk mata diklat Akuntabilitas pada Pelatihan Dasar CPNS. 27 peserta (67,50\%) peserta menyatakan bahwa model pembelajaran jigsaw efektif diterapkan untuk mata diklat Akuntabilitas pada pelatihan dasar CPNS, 4 peserta (10\%) menyatakan kurang efektif, dan 2 orang (5\%) menyatakan tidak efektif.

\section{Grafik II}

Pelatihan dasar CPNS golongan III angkatan 2

Kabupaten Bangka Tahun 2019

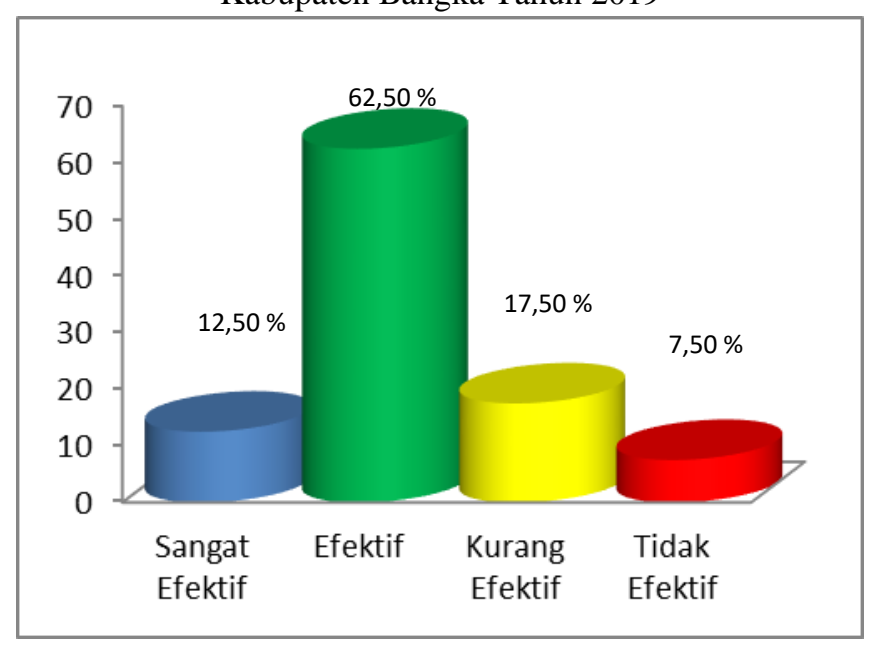

Peserta pelatihan dasar CPNS golongan III angkatan 2 Kabupaten Bangka tahun 2019 berjumlah 40 peserta, Berdasarkan hasil perhitungan kuesioner yang diisi 5 peserta (12,50\%) menyatakan penerapan model pembelajaran jigsaw untuk mata diklat akuntabilitas pada pelatihan dasar CPNS sangat efektif, 25 peserta $(62,50 \%)$ mengatakan model pembelajaran jigsaw efektif diterapkan untuk mata diklat Akuntabilitas pada pelatihan dasar CPNS. 7 peserta $(17,50 \%)$ mengatakan kurang efektif dan 3 peserta $(7,50 \%)$ menyatakan tidak efektif. 
Grafik . III

Pelatihan dasar CPNS golongan III angkatan 2

Kabupaten Bangka Selatan tahun 2019

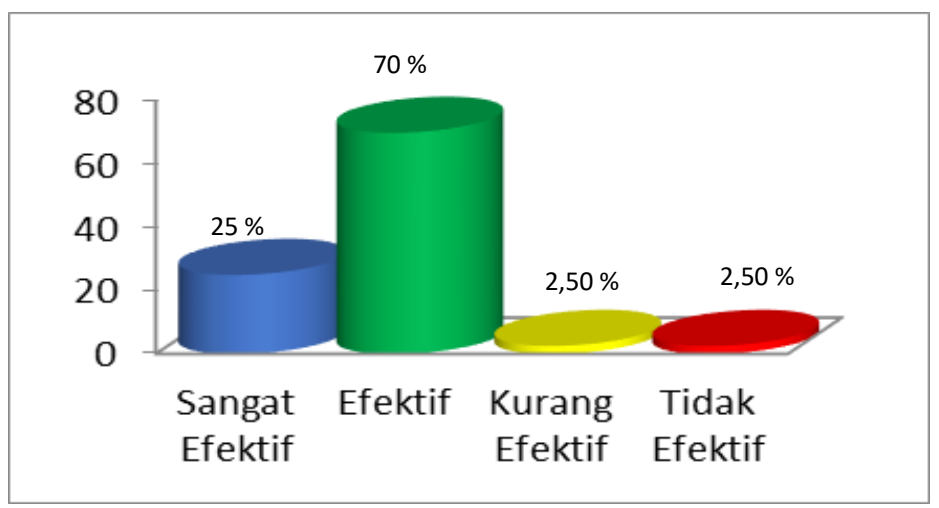

Peserta pelatihan CPNS golongan III angkatan 2 Kabupaten Bangka Selatan tahun 2019 berjumlah 40 peserta, Berdasarkan perhitungan kuesioner yang diisi 10 peserta (25\%) menyatakan model pembelajaran jigsaw sangat efektif diterapkan pada mata diklat Akuntabilitas, 28 peserta (70\%) menyatakan model pembelajaran jigsaw efektif diterapkan pada mata diklat Akuntabilitas, 1 orang (2,50\%) meyatakan penerapan model pembelajaran jigsaw kurang efektif dan 1orang $(2,50 \%)$ menyatakan model pembelajaran jigsaw tidak tepat diterapkan untuk mata diklat Akuntabilitas pada pelatihan dasar CPNS.

Grafik .IV

Pelatihan dasar CPNS golongan III angkatan 6

Provinsi Kep.Bangka Belitung tahun 2019

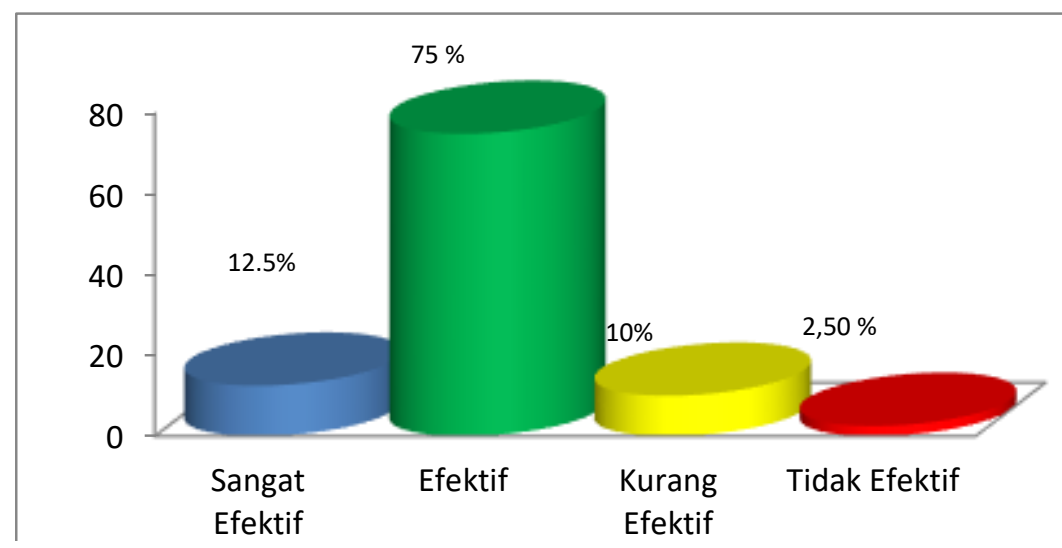

Peserta Pelatihan dasar CPNS golongan III angkatan 6 Prov.Kepulauan Bangka Belitung tahun 2019 berjumlah 40 peserta ,Berdasarkan perhitungan kuesioner yang diisi 5 peserta $(12,50 \%)$ menyatakan model pembelajaran jigsaw sangat efektif diterapkan untuk mata diklat Akuntabilitas, 30 peserta (75\%) menyatakan model pembelajaran jigsaw efektif diterapkan dalam mata diklat Akuntabilitas, 4 peserta ( 10\%) menyatakan model pembelajaran jigsaw kurang efektif diterapkan dalam mata diklat Akuntabilitas dan 1 peserta $(2,50 \%)$ menyatakan model pembelajaran jigsaw tidak efektif diterapkan untuk mata diklat akuntabilitas pada pelatihan dasar CPNS. 
Grafik.V

Pelatihan dasar CPNS golongan III angkatan 3

Kabupaten Bangka Tengah tahun 2019

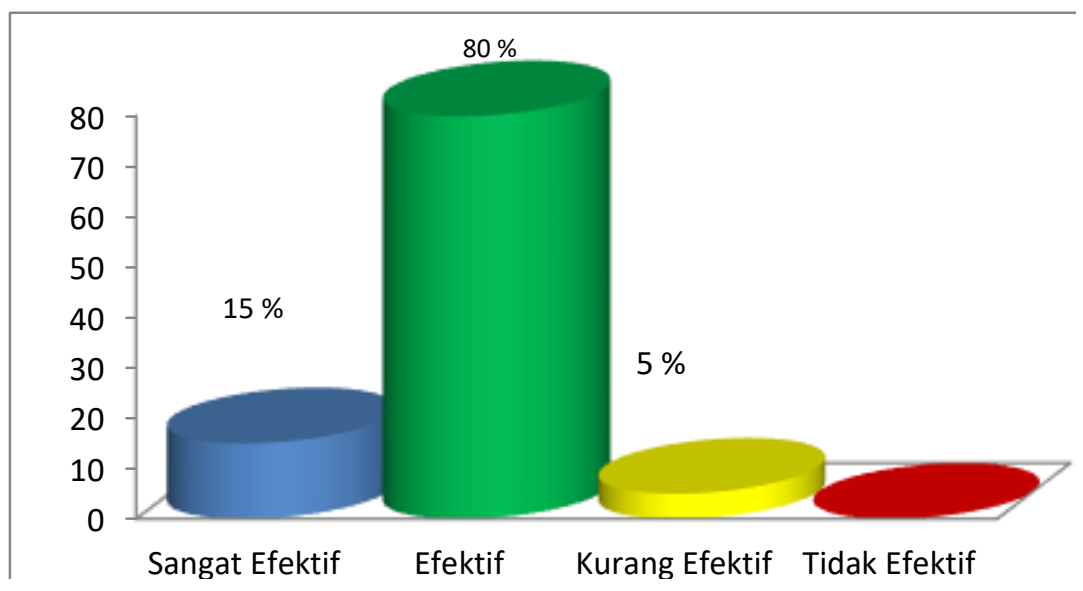

Peserta pelatihan dasar CPNS golongan III angkatan 3 Kabupaten Bangka Tengah tahun 2019 berjumlah 40 peserta, Berdasarkan hasil perhitungan kuesioner yang diisi 6 peserta (15\%) menyatakan model pembelajaran jiksaw sangat efektif diterapkan untuk mata diklat Akuntabilitas, 32 peserta ( $80 \%$ ) peserta menyatakan model pembelajaran jigsaw efektif diterapkan untuk mata diklat Akuntabilitas, 2 peserta $(5 \%)$ menyatakan model pembelajaran jigsaw kurang efektif diterapkan untuk mata diklat akuntabilitas pada pelatihan dasar CPNS.

\section{Grafik.VI}

Pelatihan dasar CPNS golongan III angkatan 6

Kabupaten Bangka Barat tahun 2019

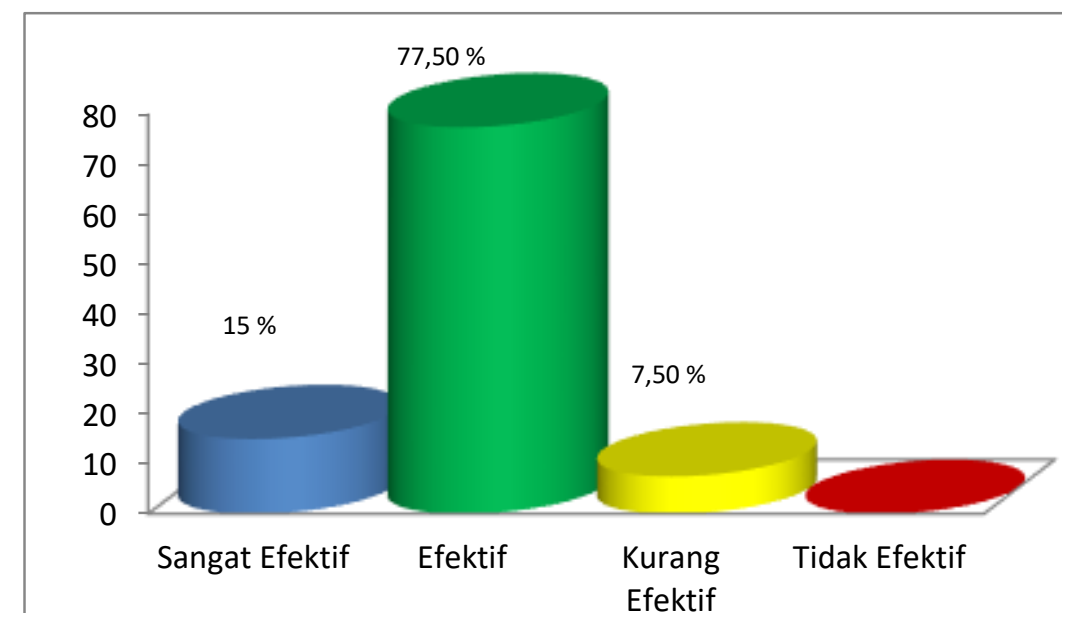

Peserta pelatihan dasar CPNS golongan III angkatan 6 Kabupaten Bangka Barat Tahun 2019 berjumlah 40 peserta. Berdasarkan perhitungan kuesioner yang diisi 6 peserta $(15 \%)$ menyatakan model pembelajaran jigsaw sangat efektif diterapkan untuk mata diklat akuntabilitas, 31 peserta $(77,50 \%)$ menyatakan model pembelajaran jigsaw efektif diterapkan untuk mata diklat akuntabilitas, 3 peserta $(7,50 \%)$ menyatakan model pembelajaran jigsaw kurang tepat diterapkan untuk mata diklat Akuntabilitas pada pelatihan dasar CPNS. 


\section{Grafik VII}

Pelatihan dasar CPNS golongan III angkatan 1

kabupaten Belitung tahun 2019

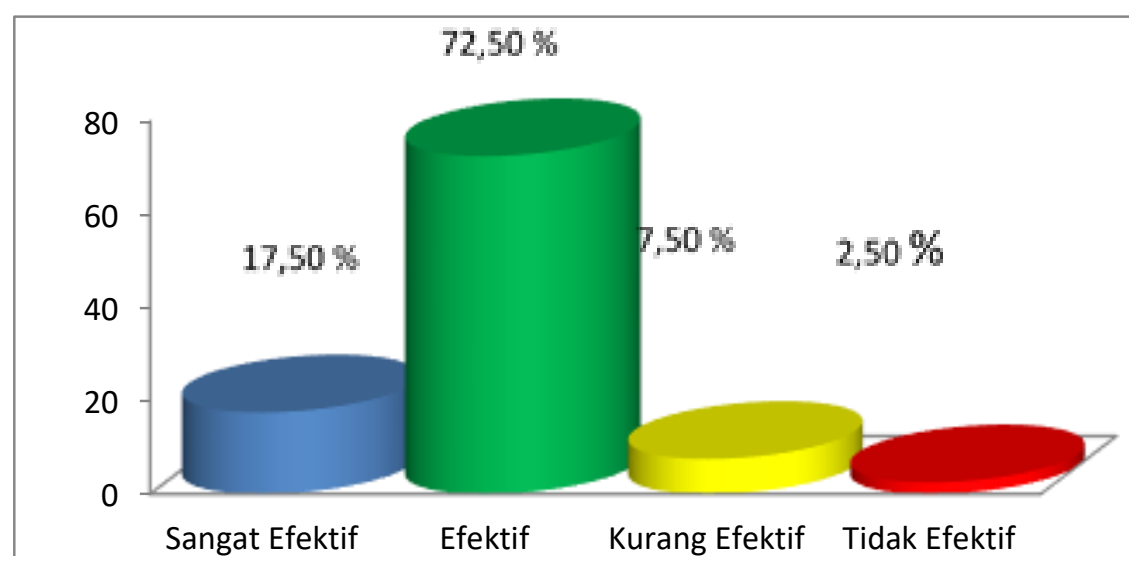

Pelatihan dasar cpns golongan III angkatan 1 Kabupaten Belitung tahun 2019 dengan jumlah 40 peserta. Berdasarkan perhitungan kuesioner yang diisi 7 peserta (17,50\%) menyatakan model pembelajaran jigsaw sangat efektif diterapkan pada untuk diklat akuntabilitas, 29 peserta $(72,50 \%)$ menyatakan model pembelajaran jigsaw efektif diterapkan pada mata diklat akuntabilitas. 3 peserta $(7,50 \%)$ menyatakan model pembelajaran jigsaw kurang efektif diterapkan untuk mata diklat akuntabilitas dan 1 peserta $(2,50 \%)$ menyatakan model pembelajaran jigsaw tidak efektif diterapkan untuk mata diklat akuntabilitas pada pelatihan dasar CPNS.

\section{Grafik VIII}

Pelatihan dasar CPNS golongan III angkatan 5

Kota Pangkalpinang tahun 2019

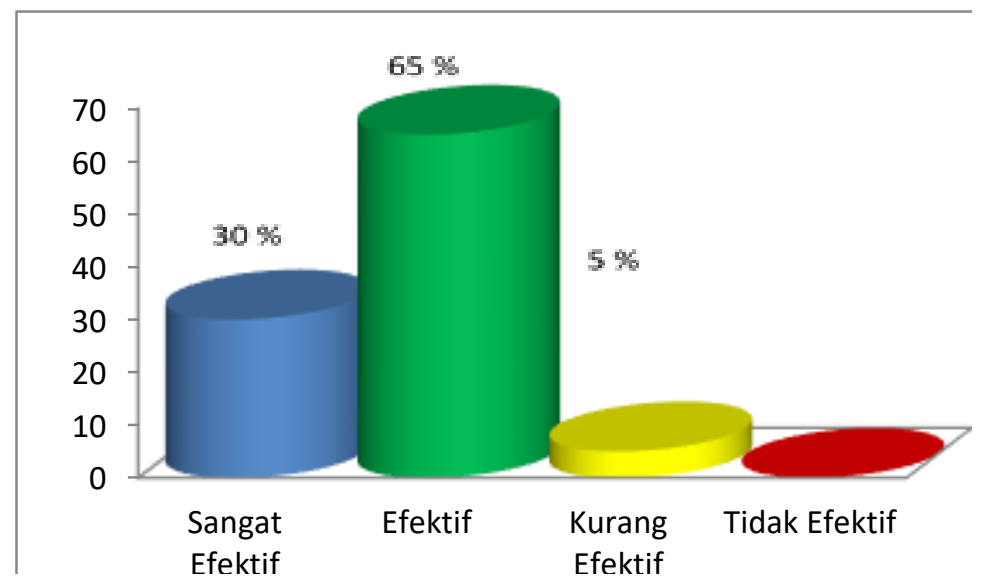

Peserta pelatihan dasar cpns golongan III angkatan 5 Kota Pangkalpinag tahun 2019 berjumlah 40 peserta. Berdasarkan hasil perhitungan kuesioner yang diisi 12 peserta (30\%) menyatakan model pembelajaran jigsaw sangat efektif diterapkan untuk mata diklat akuntabilitas, 26 peserta $(65 \%)$ menyatakan model pembelajaran jigsaw efektif diterapkan untuk diklat akuntabilitas, dan 2 peserta (5\%) menyatakan model pembelajaran jigsaw kurang efektif untuk mata diklat akuntabilitas pada pelatihan dasar CPNS. 
Grafik IX

Rekapitulasi pelatihan dasar CPNS Provinsi Kepuluan Bangka Belitung

Tahun 2019

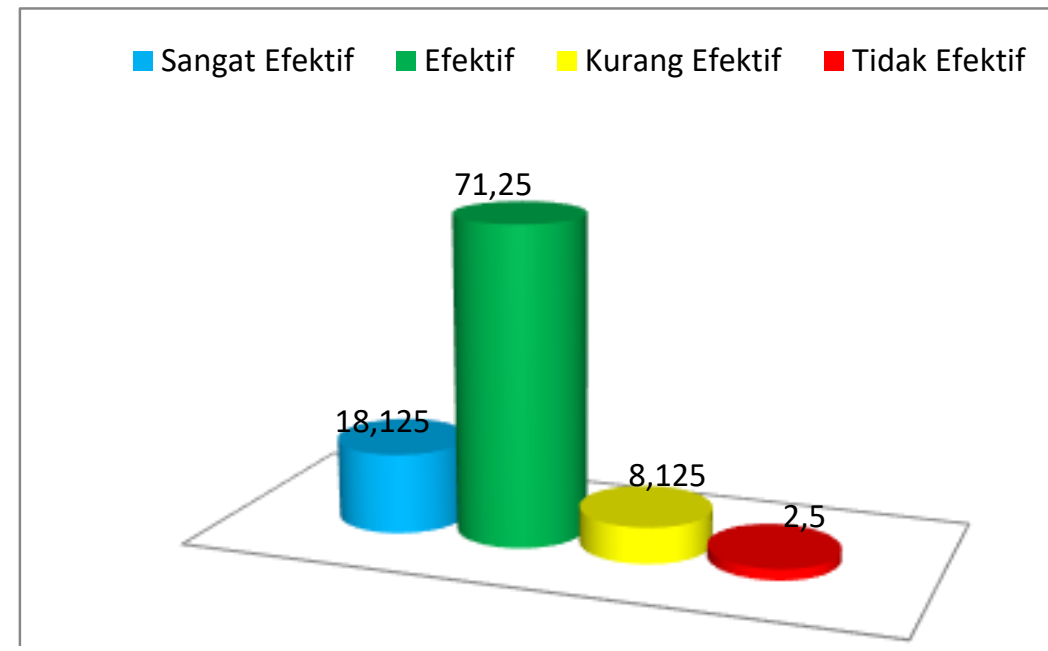

Dari 320 peserta pelatihan dasar CPNS 18,125\% peserta menyatakan model pembelajaran Jigsaw sangat efektif diterapkan untuk mata diklat Akuntabilitas .71,250\% peserta menyatakan model pembelajaran jigsaw efektif diterapkan untuk mata diklat Akuntabilitas. 8,125\% peserta menyatakan model pembelajaran jigsaw kurang efektif diterapkan untuk mata diklat Akuntabilitas. 2,50\% peserta menyatakan penerapan model pembelajaran jigsaw tidak efektif untuk diterapkan pada mata diklat Akuntabilitas pelatihan dasar CPNS.Provinsi Kepulauan Bangka Belitung tahun 2019.

\section{Kesimpulan}

Berdasarkan perhitungan dengan menggunakan skala likert dapat disimpulkan bahwa model pembelajaran jigsaw $(18,125 \%+71.250 \%)=89.375 \%)$ sangat efektif diterapkan untuk mata diklat Akuntabilitas pada pelatihan dasar CPNS Provinsi Kepuluan Bangka Belitung tahun 2019. Untuk mengetahui faktor-faktor apa saja yang membuat penerapan model pembelajaran jigsaw untuk mata diklat akuntabilitas pada pelatihan dasar CPNS Provinsi kepulauan Bangka Belitung tahun 2019 menjadi sangat efektif diperlukan penelitian lebih lanjut .

Dengan di perolehnya informasi mengenai efektivitas penerapan model pembelajaran jigsaw untuk mata diklat Akuntabilitas pada pelatihan dasar CPNS. Di Provinsi kepulauan Bangka Belitung tahun 2019 penulis menyarankan kepada rekan-rekan widyaiswara untuk lebih berinovasi mengembangkan modelmodel pembelajaran yang lainya, yang diharapkan akan lebih meningkatkan efektivitas pembelajaran.

\section{REFERENSI}

Israwati. "Efektifitas Pelaksanaan Diklat Prajabatan Pada Badan Kepegawaian Pendidikan Dan Pelatihan Kabupaten Mamasa." Mitzal, Jurnal Ilmu Pemerintahan \& Ilmu Komunikasi 4, no. 2 (2019): 171-87.

RI, LAN. “Peraturan Lembaga Adminitrasi Negara RI No. 12,” 2018.

Riyanto, Agus. Metodelogi Penelitian Kesehatan. Nuha Medika, 2019.

Shoimin, Aris. 68 Model Pembelajaran Inovatif Dalam Kurikulum 13. Yogyakarta: Ar-Ruzz Media, 2016.

Yustisia, Tim Pustaka. Undang-Undang No. 5 Tahun 2014 Tentang Aparatur Sipil Negara (ASN), 2014. 